\title{
Efeitos das Intervenções Cambiais à vista na Taxa de Câmbio R\$/US\$ de 1999 a 2008: Um Estudo de Evento
}

\author{
Roberto Meurer* \\ Felipe Wolk Teixeira** \\ Eduardo Cardeal Tomazzia***
}

\begin{abstract}
Resumo
$\mathrm{O}$ artigo analisa os efeitos das intervenções ocorridas no mercado cambial brasileiro através de operações à vista entre 1999 e 2008 sobre a taxa de câmbio R\$/US\$ utilizando a abordagem de estudo de eventos. O período foi segmentado pelos resultados de um modelo MS-VAR. Identificou-se efeito proeminente para intervenções feitas de forma contínua, em contraste a intervenções pontuais. Há indícios de que os efeitos no câmbio se dissipam rapidamente. A criação de um critério de avaliação para aceleração cambial permitiu identificar uma tendência à obtenção de sucessos nas intervenções de compras a favor da maré.
\end{abstract}

Palavras-chave: intervenções cambiais; volatilidade; taxa de câmbio; Brasil.

Códigos JEL: E32, E44, F31.

\section{Abstract}

This paper analyses interventions in the Brazilian spot foreign exchange market from 1999 to 2008 and their effects on the R $/$ US \$ exchange rate, using an event study approach. The period was divided according to a MS-VAR model. The results indicate that prolonged foreign exchange intervention have a larger effect on the exchange rate behavior, in comparison to short time intervention episodes. The results also point to quickly dissipating effects of interventions on the rate behavior. A new criterion, based on the analysis of exchange-rate acceleration, shows that the exchange rate is mainly prone to accelerate on leaning with the wind purchase intervention episodes.

Keywords: foreign exchange intervention; volatility; exchange rate; Brazil.

Submetido em Julho de 2009. Aceito em Março de 2010. O artigo foi avaliado segundo o processo de duplo anonimato além se de ser avaliado pelo editor. Editor responsável: Marcelo Medeiros. Agradecemos a dois pareceristas da RBFin pelas excelentes sugestões. O segundo autor agradece o apoio da Capes através de bolsa de mestrado. Os erros remanescentes obviamente são de nossa responsabilidade.

*Departamento de Economia da Universidade Federal de Santa Catarina - UFSC, Santa Catarina, SC, Brasil. E-mail: rmeurer@mbox1.ufsc.br

**Programa de Pós-Graduação em Economia da Universidade Federal de Santa Catarina - UFSC, Santa Catarina, SC, Brasil. E-mail: felkbr@gmail.com

***Programa de Pós-Graduação em Desenvolvimento Econômico da Universidade Federal do Paraná - UFPR, PR, Brasil. E-mail: etomazzia@yahoo.com.br 


\section{Introdução}

Desde a adoção do regime de câmbio flutuante no Brasil, em janeiro de 1999, a intervenção das autoridades monetárias no mercado cambial foi recorrente, justificada por objetivos como auxiliar no controle da inflação, ajustar o nível da taxa de câmbio e, principalmente, reduzir a sua volatilidade. A volatilidade cambial cria distorções, que são causadoras de redução de bem-estar através de dois canais primários: (1) direto, devido às pessoas apresentarem aversão às flutuações, preferirem manter um nível de consumo constante a um nível que se altera incertamente e; (2) indireto, onde a busca por hedge pelas firmas implica um prêmio de risco repassado aos preços que, sendo maiores levam à redução da demanda $\mathrm{e}$ consequentemente da produção, reduzindo o consumo e investimento a níveis inferiores ao ótimo (Bergin, 2004). Flutuações no mercado de câmbio podem interagir com políticas ativas de compra e venda de divisas pelas autoridades monetárias, com o objetivo direto de afetar a taxa ou outros como redução da exposição cambial e acúmulo de reservas internacionais. A possibilidade de interação faz com que as políticas cambiais sejam constante objeto de estudos acadêmicos, por ser importante saber se a intervenção afeta o comportamento do câmbio, através de quais canais ele opera e se atinge os seus objetivos.

Sarno e Taylor (2001) mostram a evolução dos resultados empíricos quanto à transmissão de efeitos da intervenção no câmbio através do canal de portfolio (Obstfeld, 1990). Até o fim dos anos 1970 e começo dos anos em modelos 1980, a literatura atribuía papel nulo ou de curtíssimo prazo às intervenções esterilizadas. A partir dos anos 1990, iniciando com o estudo de Dominguez e Frankel (1993), passam a existir resultados consistentes para essas intervenções. Um dos motivos primários para a inversão, segundo Sarno e Taylor (2001), foi a evolução na qualidade dos dados disponibilizados. Inovações nas ferramentas de análise e melhor confiabilidade na fonte de dados fazem com que os estudos mais recentes cheguem a resultados distintos. Também torna-se evidente que as especificidades de diferentes mercados cambiais não devem ser ignoradas.

Estudos empíricos mais recentes apresentam evidências relevantes. Taylor (2004), valendo-se de modelo de mudança markoviana, verifica o efeito de intervenções na taxa de câmbio Dólar/Marco na probabilidade de mudança de um regime instável para um regime estável e próximo da taxa de câmbio real de longo prazo. Identifica também que quanto maior o período de permanência de um regime instável, maior a probabilidade de permanência neste regime.

O BIS (2005) apresenta coletânea de artigos de membros das autoridades monetárias de vários países emergentes, com o objetivo de estudar a intervenção cambial nestes países. Entretanto, os estudos não conseguem chegar a uma conclusão sobre a real eficácia das intervenções cambiais feitas pelas autoridades monetárias dos países emergentes. No mesmo sentido, Disyatat e Galati (2007) verificam baixo efeito das intervenções no nível e volatilidade da taxa de câmbio da moeda da República Tcheca. 
Utilizando o método GMM para o caso brasileiro, Novaes e Oliveira (2007) mostram que as intervenções são ineficientes em períodos de grande volatilidade cambial. Em momentos de baixa volatilidade, entretanto, tanto os mercados à vista como futuros apresentam grande resposta às intervenções, ainda maior que às demais ações de política monetária. Entre outros estudos para o caso brasileiro, destaca-se o de Araujo e Goldfajn (2004), que testam o efeito de intervenções sobre o retorno e a volatilidade condicional cambial por meio de modelo EGARCH, considerando a endogeneidade da variância em relação às intervenções. Entre suas conclusões, verificam eficácia das intervenções no nível da taxa de câmbio e em reduzir a volatilidade. Outro resultado importante é que, se não considerada esta endogeneidade, o efeito verificado na volatilidade é inverso.

Gnabo et alii (2008) comparam as intervenções cambiais da República Tcheca e Brasil por modelo de fricções, a partir da adoção do regime de metas de inflação em ambos os países. Entre suas principais conclusões estão: (i) ambos os países utilizam as intervenções principalmente para reduzir a volatilidade cambial, mesmo que para o Brasil um objetivo adicional seja aproximar a taxa de câmbio de seu equilíbrio de médio prazo; (ii) identificam uma função de reação com forte efeito threshold, de modo que as autoridades monetárias de ambos os países atuam predominantemente para depreciar a sua moeda; (iii) no Brasil, as intervenções não parecem estar sendo coordenadas com a política monetária, o inverso do observado na República Tcheca.

Menkhoff (2010) apresenta um survey de estudos empíricos que utilizam dados de alta frequência (intra-diários). $\mathrm{O}$ autor atesta a utilidade desta abordagem em separar o efeito das intervenções de outros fatores nas variações observadas da taxa de câmbio, assim como em resolver o problema da endogeneidade da intervenção em relação à variância da taxa de câmbio. Entre suas principais conclusões, verifica o claro efeito das intervenções no nível da taxa de câmbio. Quanto ao efeito de intervenções na volatilidade da taxa de câmbio, verificou um importante grau de endogeneidade, uma vez que as intervenções são motivadas pela alta volatilidade da taxa de câmbio. Quanto aos canais de transmissão das intervenções, o canal da sinalização parece ser o mais plausível em explicar o grande poder de intervenção verificado por intervenções de pequeno volume, se comparado ao total de transações nos mercados de câmbio.

Dada a variedade de resultados encontrados na literatura, ainda não há uma concordância quanto ao efeito das intervenções (Schwartz, 2004), o que não impede os bancos centrais de intervirem nos mercados cambiais, o que pode ser justificado pela inadequação dos instrumentos de análise das intervenções ou porque os efeitos das intervenções são menores que o conjunto de fatores diversos que também agem sobre o câmbio.

O presente artigo se propõe a verificar se as intervenções no mercado brasileiro de câmbio entre 1999 e 2008 afetaram o comportamento da taxa de câmbio $\mathrm{R} \$$ /US\$. O período de análise foi segmentado de acordo com a os resultados de um modelo de Mudança de Regimes Markoviano (Hamilton, 1989, Krolzig, 2005), 
separando os diferentes ciclos de comportamento cambial. Esta segmentação permite a captação de nuances específicas a cada sub-período identificado. Foi então utilizada a abordagem de estudos de eventos, através de adaptações do método proposto por Fatum e Hutchinson (2003, 2006), que levaram à elaboração de um novo critério de análise que visa identificar a possível existência de efeito-aceleração na taxa de câmbio, após a execução de intervenções. De forma complementar, as amostras foram analisadas com o teste de Mann-Whitney-Wilcoxon.

Os resultados indicam que as intervenções realizadas de forma contínua apresentam maior capacidade de afetar o comportamento do câmbio. Foram encontrados indícios de que as intervenções têm efeito de curto prazo, os critérios identificam concentração de resultados significantes nas janelas de um a dois dias após as intervenções, o que foi confirmado pelo teste de Mann-Whitney-Wilcoxon.

$\mathrm{O}$ artigo foi organizado em 4 seções, incluindo esta introdução. A próxima seção especifica a fonte dos dados e as ferramentas utilizadas para os testes estatísticos. Na terceira seção são apresentados os resultados do artigo e na última os comentários finais.

\section{Dados e Metodologia}

Intervenções representam o ato da autoridade monetária de interferir no mercado de moeda externa, através de compras ou vendas de divisas no mercado spot ou futuro, de forma a alterar o comportamento da taxa de câmbio (Schwartz, 2004). Essas intervenções podem ser esterilizadas, quando há uma operação que anula o efeito da intervenção sobre a base monetária, ou não-esterilizadas, quando gera alteração na base monetária (Neely, 2005). As intervenções feitas no mercado de câmbio brasileiro são esterilizadas, ou seja, seu efeito sobre a base monetária é neutralizado por outra operação, em geral de títulos públicos.

\subsection{Dados}

Os três principais mecanismos de intervenção no mercado de câmbio brasileiro são leilões no mercado de dólar à vista, negociação de títulos da dívida indexados ao dólar e contratos de swap. Neste artigo são analisadas as intervenções no mercado à vista.

No demonstrativo mensal de variação das reservas internacionais, o Banco Central do Brasil (BACEN) divulga as intervenções cambiais no mercado à vista, porém, esta série não está disponível com periodicidade diária. Utilizou-se, então, a série dos Fatores Condicionantes da Base Monetária - Conta Operações com o Setor Externo, que também contabiliza a compra e venda de divisas feitas pelas autoridades monetárias. Como existe uma defasagem de dois dias úteis entre as operações com dólares e a liquidação dessas operações em reais, ou seja, caso o BACEN compre ou venda dólar no mercado à vista em um dia $\mathrm{D}$ a conta Operações com o Setor Externo é afetada apenas em D+2, a série foi ajustada para compensar a defasagem. A série apresenta operações do BACEN de aproximadamente US\$ 312 bilhões na direção de compra e US\$ 121 bilhões na direção de vendas. Deve 
ser notado que essa série não inclui as operações feitas pelo Tesouro Nacional, ocorridas entre 2003 e 2008, totalizando compras de aproximadamente US\$ 55 bilhões. Estes dados são divulgados no Demonstrativo de Variação de Reservas Internacionais das Notas Para Imprensa - Setor Externo, do Banco Central. Não foi possível a utilização dos dados de intervenção do Tesouro Nacional devido à indisponibilidade dos mesmos em frequência diária.

Para a série de câmbio, utilizou-se a taxa média diária de venda divulgada pelo Banco Central. A série dos Fatores Condicionantes da Base Monetária foi dividida pela série das taxas de câmbio para chegar ao valor das intervenções em dólares. O período de análise vai de 05/01/1999 até 31/12/2008. Visto que nesse intervalo há modificações econômicas e políticas que afetam o comportamento do câmbio, testou-se a ocorrência de quebras estruturais na série, através de um modelo de Mudança de Regimes Markoviano - MS-VAR. As modificações que afetam a economia e os mercados financeiros tornam plausível a ocorrência de diferentes regimes no mercado cambial. O que se busca com a utilização de um modelo paramétrico para segmentar a série de tempo foi evitar a arbitrariedade implícita de uma inspeção visual ou com base em informações jornalísticas. Segundo o estudo de Dueker e Neely (2007), os modelos de Mudança de Regime Markoviano são de desempenho superior em análises univariadas das taxas de câmbio, uma vez que modelam melhor os retornos cambiais em um ambiente de risco variável, além de constituírem modelos não-lineares. Para a amostra utilizada neste artigo, testes de quebra em modelos ARMA sofrem com a não-normalidade dos resíduos, conforme testado para diversas especificações, o que invalidaria os resultados de testes de quebra tradicionais.

\subsection{Ciclos cambiais no período}

As datas para a segmentação da série foram obtidas mediante a análise dos resultados de testes de Mudança de Regime Markoviano - MS - (Krolzig, 1997), utilizando o pacote OX MSVAR1.32a, disponibilizado por Krolzig (2005). A hipótese fundamental do modelo é que os parâmetros da estimação dependem do regime vigente. Caso haja uma mudança não-observada de regime, os parâmetros se tornam variantes no tempo. Esses parâmetros só serão invariantes se condicionados ao regime, designado por $S_{t}$. A série pode passar por inúmeras alterações de regimes e a probabilidade de troca de regimes é designada pela equação (1).

Após a estimação dos regimes e probabilidades, dois algoritmos filtram e suavizam as probabilidades. Os modelos MS podem detectar alterações na média (MSM), variância (MSH) e intercepto (MSI) da variável de interesse, o retorno da taxa de câmbio no caso deste trabalho. $\mathrm{O}$ modelo escolhido com base nos critérios de seleção AIC, SBC e SC foi o MSMH com 3 regimes (Tabela 1).

$$
P \downarrow i j(S(t))=P(s \downarrow(t+1)=j \mid s \downarrow t=i \dashv),
$$

onde $\sum N j=1 p_{i j}=1 \forall i, j \in\{1, \ldots, N\}$ 
Após a estimação dos regimes e probabilidades, dois algoritmos filtram e suavizam as probabilidades. Os modelos MS podem detectar alterações na média (MSM), variância (MSH) e intercepto (MSI) da variável de interesse, o retorno da taxa de câmbio no caso deste trabalho. O modelo escolhido com base nos critérios de seleção AIC,SBC e SC foi o MSMH com 3 regimes (Tabela 1).

Tabela 1

Critérios de seleção para os modelos MS-VAR

\begin{tabular}{cccc}
\hline Modelo & AIC & SBC & SC \\
\hline MSI(2) & $-6,1511$ & $-6,1461$ & $-6,1372$ \\
\hline MSI(3) & $-6,4811$ & $-6,4718$ & $-6,4556$ \\
\hline MSM(2) & $-6,1511$ & $-6,1461$ & $-6,1372$ \\
\hline MSM(3) & $-6,4811$ & $-6,4718$ & $-6,4555$ \\
\hline MSH(2) & $-6,7323$ & $-6,7272$ & $-6,7183$ \\
\hline MSH(3) & $-6,8362$ & $-6,8269$ & $-6,8106$ \\
\hline MSMH(2) & $-6,7342$ & $-6,7283$ & $-6,7179$ \\
\hline MSMH(3) & $-6,8383$ & $-6,8274$ & $-6,8081$ \\
\hline
\end{tabular}

Os modelos MSH(3) e MSMH(3) apresentaram resultados muito próximos. Optou-se pelo modelo MSMH(3), mais completo, por ser capaz de identificar mudanças na média e na variância dos retornos. A inclusão da variância na especificação dos regimes é conceitualmente importante, uma vez que existe uma expectativa de que períodos de maior variância estejam associados a efeitos de intervenção diversos de períodos "normais".

$\mathrm{O}$ teste de linearidade acusou não-linearidade do modelo, o que confirma a opção da análise por MS-VAR, uma vez que os parâmetros mudam de um regime para o outro. Os resíduos do MS-VAR testado se mostraram bem comportados, sendo não correlacionados, homoscedásticos e normais. Isso pode ser verificado nos gráficos de função de auto-correlação e auto-correlação parcial, de densidade de distribuição e no diagrama quantil-quantil (QQ) dos resíduos (figura 1). 


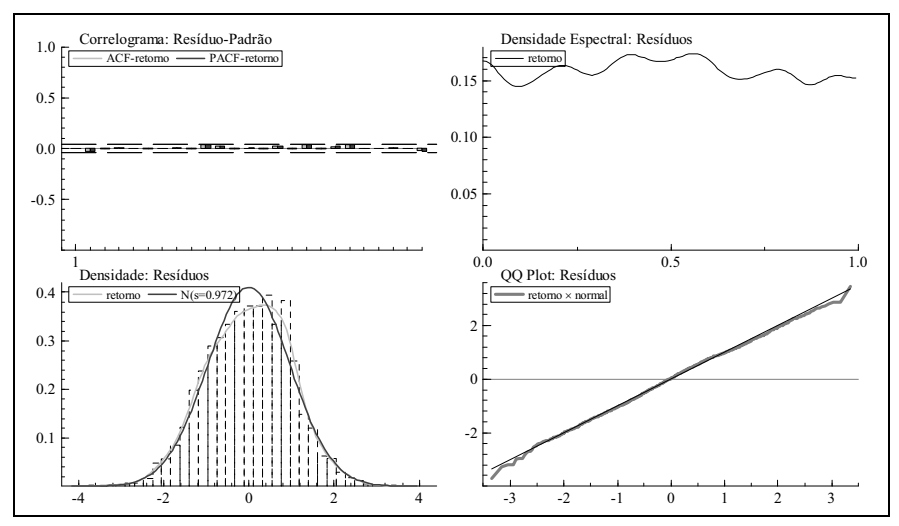

Figura 1

Testes dos resíduos - MSMH(3) AR(1) - retorno cambial

O primeiro dos três 3 regimes contém retornos próximos de zero (estatisticamente não diferentes de zero, conforme a estatística $t$ ), o segundo apresenta os retornos negativos e o último retornos positivos. Para os componentes autoregressivos (AR) testou-se a janela de 1 a 6 defasagens, mas não foi identificada diferença significativa entre os modelos. Os resultados mostrados na Tabela 2 são referentes ao modelo MSMH(3)AR(1). O componente auto-regressivo mostra que a variação da taxa de câmbio é aproximadamente 0,12 da variação do dia anterior.

Tabela 2

Coeficientes dos regimes - MSMH(3) AR(1)

\begin{tabular}{cccc}
\hline & Coef. & Erro-padrão & Est. $t$ \\
\hline Regime 1 & 0,0002 & 0,0004 & 0,5576 \\
\hline Regime 2 & $-0,0006$ & 0,0002 & $-3,3259$ \\
\hline Regime 3 & 0,0059 & 0,0025 & 2,3122 \\
\hline Retorno (-1) & 0,1174 & 0,0209 & 5,6059 \\
\hline
\end{tabular}

A figura 2 mostra o resultado do modelo MSMH(3)AR(1), em que é possível ver a estabilidade do regime em função do tempo, ou seja, no gráfico estão inseridas as probabilidades (filtrada, suavizada e prevista) de não haver trocas de regimes. Quanto mais próximo de 1, maior é a probabilidade de o regime não sofrer alterações. Observa-se que o período é composto, majoritariamente, por alternância entre retornos nulos e negativos. Os retornos positivos são menos frequentes. 


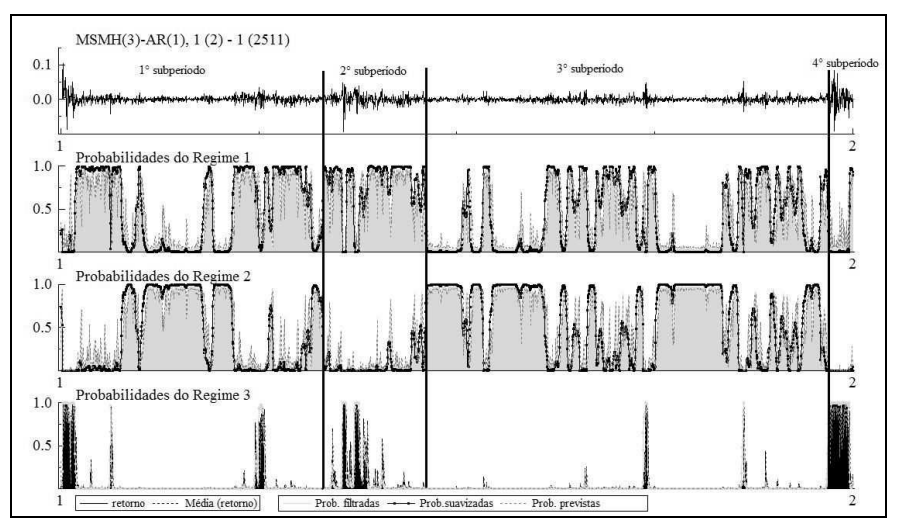

Figura 2

Mudanças de regimes - MSMH(3) AR(1) - retorno cambial

O período de 05/01/1999 a 31/12/2008 foi dividido em 4 sub-períodos (Tabela 3). Não foi possível realizar uma divisão pura de regimes, uma vez que há grande quantidade de transições entre regimes. Deste modo, procurou-se separar os períodos com menor variância, caracterizados pelo Regime 2, dado o fato das apreciações da moeda brasileira ocorrerem de modo gradual e com a ausência de choques. Os intervalos definidos são compatíveis com a conjuntura econômica e política, o que dá maior segurança à aplicação dos testes não paramétricos para os períodos segmentados de maneira não-idiossincrática. O intervalo inicial, de 05/01/1999 a 25/04/2002, vai da adoção do câmbio flutuante até o início da minicrise cambial das eleições presidenciais de 2002, com o rápido crescimento do candidato Luis Inácio Lula da Silva nas pesquisas de intenção de voto. O intervalo de 26/04/2002 a 11/08/2003 é caracterizado por alternância de regimes, indicando a volatilidade elevada no período eleitoral e início do governo de Lula. O final deste período pode ser interpretado como a conquista da confiança pelo governo Lula, dada a ausência de surpresas de política econômica. O terceiro período, de 12/08/2003 a 08/09/2008, define um ciclo longo de apreciação suave do câmbio favorecido pelo cenário externo benéfico, com uma política econômica declarada de aumentar as reservas internacionais e reduzir a exposição cambial do setor público (Bacen - Banco Central do Brasil, 2007). O último período, de 09/09/2008 a 31/12/2008 é de retornos positivos, com a depreciação do Real frente ao Dólar no contexto da crise financeira internacional. 
Tabela 3

Subperíodos: 1999 a 2008

\begin{tabular}{cc}
\hline 1 & $05 / 01 / 1999-25 / 04 / 2002$ \\
\hline 2 & $26 / 04 / 2002-11 / 08 / 2003$ \\
\hline 3 & $12 / 08 / 2003-08 / 09 / 2008$ \\
\hline 4 & $09 / 09 / 2008-31 / 12 / 2008$ \\
\hline
\end{tabular}

\subsection{Identificação de eventos e critérios de análise}

Os eventos de interesse são representados pelos dias onde há intervenção no câmbio. Uma característica da série obtida é que as intervenções apareceram com elevada frequência e muitas vezes em dias consecutivos. Algumas medidas foram tomadas visando reduzir o ruído e contaminação entre as janelas de estimação. As intervenções consecutivas foram aglutinadas sob um mesmo evento, um cluster de intervenção. As intervenções são separadas quando há a ocorrência de um dia útil entre as intervenções. Fatum e Hutchinson (2003) testam diferentes distâncias entre as intervenções, de um dia útil até 10 dias. Essa alternativa foi aqui testada, mas implicou em condensar, sob um mesmo evento muitos meses consecutivos, com poucos resultados significativos, o que a inviabilizou. No caso da junção de diversas intervenções em um único evento, a data considerada é dada pelo período total de intervenção. Apesar da adoção desse critério, ocorreu grande sobreposição de eventos, muitas vezes até em direções opostas, com uma intervenção de compra seguida por uma intervenção de venda. Para restringir de forma mais severa o ruído, definiu-se um filtro no qual apenas as intervenções acima de US\$ 200 milhões seriam consideradas. Isto não gerou muita perda de representatividade dos dados, porque os dados filtrados ainda representam $80 \%$ do volume total de intervenções.

A janela de estimação, que contém os dias pré e pós evento onde o câmbio é analisado, foi testada para um, dois, cinco, dez e vinte dias úteis antes e após as intervenções. As intervenções foram também classificadas em contra e a favor da maré. Para isso, foi adotado o seguinte procedimento de análise dos dados, baseado nos critérios de (Fatum e Hutchinson, 2003, 2006):

$$
\text { Se }\left\{E_{i}>0 \text { e } \Delta S_{i} \text { pré-evento }<0\right\},
$$

então intervenção de compra contra a maré

$$
\text { Se }\left\{E_{i}<0 \text { e } \Delta S_{i} \text { pré-evento }>0\right\},
$$

então intervenção de venda contra a maré

$$
\text { Se }\left\{E_{i}>0 \text { e } \Delta S_{i} \text { pré-evento }>0\right\},
$$

então intervenção de compra a favor da maré 


$$
\text { Se }\left\{E_{i}<0 \text { e } \Delta S_{i} \text { pré-evento }<0\right\},
$$

então intervenção de venda a favor da maré

onde:

$E_{i}$ é a intervenção cambial; valores positivos (negativos) representam compra (venda) de dólares, no evento $i$.

$\Delta S_{i}$ pré-evento é a variação cambial na janela de estimação anterior ao evento $i$ em questão.

O objetivo da análise é comparar a direção da operação cambial com a direção da taxa de câmbio no período anterior à mesma. Caso sejam em direções distintas, variação cambial negativa seguido de intervenção de compra ou variação cambial positiva seguida de intervenção de venda, o evento é classificado como contra a maré; caso sejam na mesma direção o evento é classificado como a favor da maré.

Não é necessário que as intervenções sejam contra ou a favor da maré, porque o objetivo da intervenção pode não ser influenciar a taxa de câmbio, como aumento ou redução de reservas internacionais, por exemplo. Dada essa possibilidade, testou-se também um critério que permite a classificação da intervenção como neutra, através da construção de um intervalo para a média e diferentes desviospadrão dos retornos. Os resultados obtidos implicaram em classificação de grande parte das intervenções como neutras, não possibilitando a aplicação dos critérios de análise dispostos na subseção a seguir.

\subsection{Critérios de análise}

Adotando a metodologia proposta por Fatum e Hutchinson (2006) como base, foram utilizados três critérios para avaliar cada episódio de intervenção: volatilidade, direção e suavização/aceleração.

Para todos os critérios, os testes foram feitos de forma casada. Sendo assim, a nomenclatura $D 1$ representa a comparação entre o dia $D+1$, um dia após o evento, com $D-1$, um dia antes do evento; já $D 2$ representa a comparação entre o intervalo $[D+1 ; D+2]$, após o evento, com o intervalo $[D-1 ; D-2]$, antes do evento, e assim sucessivamente.

a) critério de volatilidade Segundo este critério, um evento é bem sucedido quando a intervenção é capaz de reduzir a volatilidade cambial, ou seja, a volatilidade pós-intervenção é menor que a pré-intervenção. A medida utilizada para mensuração de volatilidade é o desvio-padrão do intervalo de retornos cambiais (Fatum e Hutchinson, 2006). Sendo assim, tem-se que: $\sigma_{i \text { pós-evento }}^{2}<\sigma_{i}^{2}$ pré-evento 
b) critério de direção Testa-se a direção que o câmbio tomou após a intervenção; segundo este critério, uma intervenção é bem sucedida quando:

$$
\left\{E_{i}>0 \text { e } \Delta S_{i+}>0\right\} \text { ou }\left\{E_{i}<0 \text { e } \Delta S_{i+}<0\right\}
$$

Uma intervenção na direção de compra de dólares $\left(E_{i}>0\right)$ deve ser seguida por uma depreciação da moeda brasileira (uma variação percentual média positiva na taxa de câmbio, $\Delta S_{i+}>0$, a taxa de câmbio deve aumentar); já uma intervenção na direção de venda de dólares deve ser seguida por uma apreciação do real (variação percentual negativa, a taxa diminui).

O critério é interessante para se testar intervenções contra a maré, visto que, no caso de sucesso, ocorre uma "reversão" na direção da taxa de câmbio (Fatum e Hutchinson, 2006). Já para os casos a favor da maré, o critério de direção não é suficiente: dada uma intervenção de compra a favor da maré onde ocorre $\Delta S_{i+}>0$, apesar da variação positiva, ela pode significar uma variação cambial pós-evento inferior à variação pré-evento, um efeito suavização. Nesse caso a intervenção não pode ser classificada como um sucesso. O mesmo problema de avaliação ocorre para intervenções de venda a favor da maré. De forma a completar a avaliação, foi elaborado o critério de suavização e aceleração.

c) critério de suavização e aceleração Esse critério apresenta um complemento frente ao utilizado em Fatum e Hutchinson (2006): aqui compara-se o módulo das médias pré e pós-evento, ao invés das médias sem módulo. Essa modificação permite identificar acelerações no comportamento dos retornos cambiais. Isso se torna útil para analisar o efeito de intervenções feitas a favor da maré. A metodologia proposta por Fatum e Hutchinson (2003, 2006) não permite essa distinção, identificando apenas os efeitos de suavizações no câmbio. Tem-se então que, caso a variação pós-evento, em módulo, seja menor (maior) que a pré-evento, diz-se que ocorreu uma suavização (aceleração) na taxa de câmbio:

$$
\text { Se }\left\{\left|\Delta S_{i+}\right|<\Delta S_{i-} \mid \square\right\} \text {, há suavização }
$$

$$
\text { Se }\left\{\left|\Delta S_{i+}\right|>\Delta S_{i-} \mid \square\right\} \text {, há aceleração }
$$

Em uma compra a favor da maré (ou seja, o câmbio se depreciou no préevento), são consideradas bem sucedidas apenas as intervenções que se relacionem a uma elevação na taxa de depreciação. Já uma intervenção de venda a favor da maré é tida como sucesso se está relacionada a uma elevação na taxa de apreciação. Esses dois casos estão exemplificados na figura 3, casos A e B, respectivamente. 


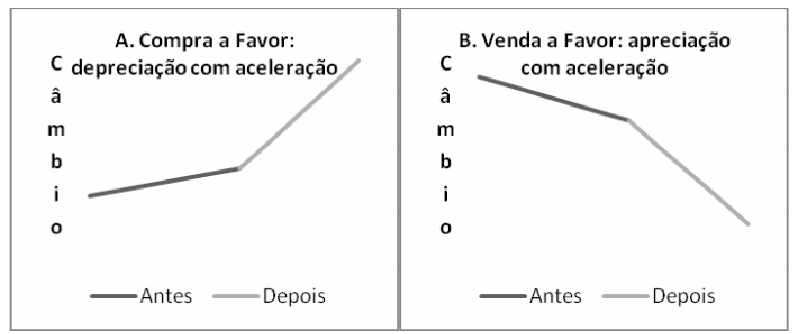

Figura 3

Sucesso para compras (A) e vendas (B) a favor da maré

Fonte: elaborado pelos autores.

Nas compras contra a maré (o câmbio apreciou no pré-evento), são consideradas bem sucedidas as intervenções cujos resultados sejam de: (A) apreciação com suavização, (B) depreciação com suavização e (C) depreciação com aceleração. Essas condições estão exemplificadas na figura 4, casos A, B e C, respectivamente.

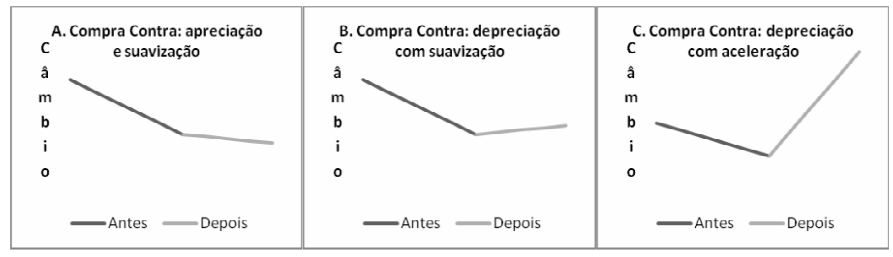

\section{Figura 4}

Sucessos para compras contra a maré

Fonte: elaborado pelos autores.

No caso de vendas contra a maré, onde o câmbio depreciou no pré-evento, o sucesso é condicional a um dos seguintes resultados: (a) depreciação com suavização, (b) apreciação com suavização e (c) apreciação com aceleração. Essas condições estão explicitadas na figura 5, em A, B e C, respectivamente. 


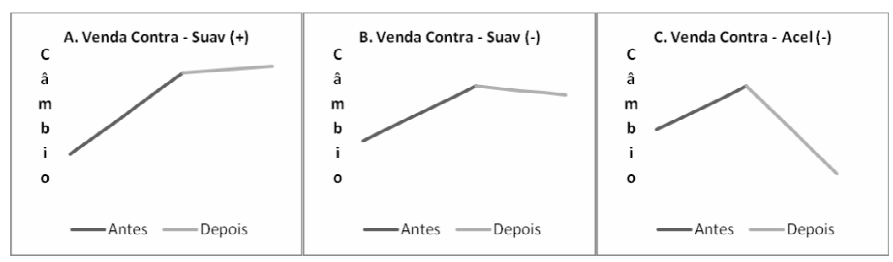

Figura 5

Sucessos para vendas contra a maré

Fonte: elaborado pelos autores.

\subsection{Testes não paramétricos}

De forma a complementar os resultados obtidos a partir desses critérios, foram realizados outros testes estatísticos. Visto que a série de variação cambial diária muitas vezes não segue a distribuição normal, porque as observações presentes frequentemente não são independentes das observações passadas (Coppes, 1995), recorreu-se a um conjunto de testes não-paramétricos, que não fazem suposições acerca da distribuição da série.

Um teste não-paramétrico muito difundido é o teste de sinal (sign test), que pode ser utilizado para testar se modificações na direção da taxa de câmbio ou amortecimentos de tendência após as intervenções são aleatórios ou não. Um teste mais robusto, utilizado no presente trabalho, é o de rankings sinalizados de Wilcoxon (Ranked Sign Test, Wilcoxon (1945)), que utiliza a grandeza da diferença entre as observações e não apenas o sinal das mesmas. No teste, as diferenças entre as observações e a mediana são ordenadas de acordo com a grandeza. A hipótese nula é de que a soma dos rankings acima e abaixo da mediana são iguais. O teste de Mann-Whitney-Wilcoxon (Lehman, 1988) é similar ao acima, porém, podem-se comparar medianas, médias ou variâncias de séries diferentes, observando se de fato há diferenças de comportamento entre as mesmas.

\section{Resultados}

Os sucessos obtidos segundo cada critério foram testados de acordo com uma distribuição binomial (Fatum e Hutchinson, 2003). Testou-se também se há diferença nesses resultados dada a duração das intervenções. Para isso foi elaborada a seguinte classificação para os eventos: (a) todos os eventos de intervenção, independente da duração; (b) apenas os eventos com um dia de duração e (c) apenas os eventos com duração superior a um dia, ou seja, episódios que apresentem intervenções em dias sequenciais. 
A listagem dos eventos identificados encontra-se na tabela 4 do anexo, e as tabelas de resultados dos critérios na sua sequência. Não foram inseridas nas tabelas as intervenções com ocorrência menor ou igual a duas por subperíodo. Por exemplo, se no período 1 ocorreram apenas dois episódios de compra a favor da maré, eles não se encontram na tabela. Com isto procurou-se facilitar a leitura, mas os dados integrais podem ser obtidos com os autores.

\subsection{Critério de volatilidade}

A análise do período inteiro, sem segmentação de dados, tabela 5 no anexo, identifica redução de volatilidade na janela D1 nos eventos de intervenções a favor da maré, tanto de compra (significante a 10\%) como de venda (5\%). Esse efeito é dissipado quando são considerados os dados para janelas mais duradouras ( $D 2$ ou mais). Observa-se que as intervenções de venda estão vinculadas à redução de volatilidade nas janelas $D 5, D 10$ e $D 20$ (significantes a $5 \%, 5 \%$ e $1 \%$, respectivamente).

A aplicação do teste nos subperíodos, tabela 5 no anexo, permite identificar a relevância na redução de volatilidade vinculadas às operações de venda contra a maré no subperíodo 2 (significantes a 10\%) e as operações de compra a favor da maré, no subperíodo 3 (também a 10\%). A redução de volatilidade é frequente apenas na janela de 1 dia após a intervenção, um indicativo que o efeito na volatilidade cambial pode ser de curto prazo. Para o quarto subperíodo, encontra-se redução de volatilidade para intervenções de venda contra a maré apenas para a janela $D 20$ (significante a $1 \%$ ).

Outra característica marcante reside na concentração de resultados significantes para a série de intervenções com duração superior a um dia, um sinal de que as intervenções duradouras podem ter maior capacidade de afetar a volatilidade do câmbio. Este resultado pode ser consequência da sinalização da possibilidade de as intervenções não se esgotarem rapidamente, influenciando o comportamento do mercado.

\subsection{Critério de direção}

Para a análise de direção, deve ser lembrada a fraca importância de resultados significantes para as operações a favor da maré. Mesmo que se tenha obtido sucesso no critério de direção, pode ter ocorrido uma suavização da variação cambial, ao invés de aceleração. Para as intervenções contra a maré, um sucesso indica uma significante reversão na direção cambial.

Novamente as intervenções mais duradouras parecem ser mais eficazes em afetar o comportamento da taxa de câmbio: foram obtidos resultados significantes no grupo de eventos com duração superior a um dia (tabela 6 do anexo). Porém, parte dos sucessos é referente a intervenções a favor da maré, onde o critério é insuficiente para indicar que a intervenção afetou, de fato, o comportamento cambial. 
Ainda assim, considerando a série sem divisão em sub-períodos (tabela 6), são obtidos resultados referentes às intervenções contra a maré na janela $D 2$, na direção de compra e de venda, significantes a $10 \%$ e $5 \%$, respectivamente. Esses resultados se dissipam à medida em que a janela de testes é expandida. Foi identificada também reversão na direção dos retornos vinculadas a operações de compras contra a maré durante o sub-período 3 e vendas contra a maré no sub-período 4 (significantes a $10 \%$ e $5 \%$, respectivamente). As intervenções de venda do subperíodo 2 não se mostraram capazes de causar reversão na direção cambial.

\subsection{Critério de aceleração e suavização}

Como já explicado, a probabilidade de sucesso nesse critério é diferente para as intervenções a favor e contra a maré ( 1 de 4 casos e 3 de 4 casos). Dada essa característica, o total de intervenções de compra, venda ou soma das duas não foi testado conjuntamente.

Para a série sem segmentação em sub-períodos e com todos os eventos, independente de duração, são encontrados resultados significantes na janela $D 1$, uma indicação de efeito aceleracionista nas operações de compras a favor da maré, assim como para o total de intervenções a favor, ambas significantes a 5\% (tabela 7 do anexo). Os sucessos nas intervenções contra a maré - efeito suavização - ocorrem nas janelas de duração mais longa, principalmente $D 10$ e $D 20$, significando uma possível defasagem temporal entre a intervenção e o efeito no câmbio, quando a mesma está agindo contra a tendência do câmbio. A análise com sub-períodos permite a identificação de efeito aceleração nas intervenções de compra efetuadas durante o terceiro sub-período (significante a 10\%).

Similarmente aos outros critérios, as intervenções mais duradouras apresentam resultados mais robustos em relação às intervenções com apenas um dia de duração.

\subsection{Teste de Mann-Whitney-Wilcoxon (MWW)}

Para este teste cada série de intervenções foi dividida em duas: uma série contendo apenas os retornos das datas de interesse e a outra contendo as observações remanescentes, ou seja, a série de retornos excluindo as datas de interesse. A data de interesse representa aqui os períodos onde foi buscada a identificação de mudança no comportamento cambial. A hipótese nula deste teste é que as duas séries foram extraídas de uma mesma população. No presente artigo, a hipótese nula seria que os retornos próximos das datas de interesse não diferem dos retornos nas demais datas. A diferença entre as séries pode ser detectada através de diferenças na média, mediana ou variância, apesar de o teste ser chamado de teste de igualdade entre as medianas. A rejeição da hipótese nula pode indicar uma alteração no processo de formação da taxa de câmbio devido às intervenções (Meurer et alii, 2007). 
As seguintes datas foram testadas, considerando que a data base é o dia da intervenção $(D 0), D-1$ representa o dia anterior à intervenção, $D+1$ o dia posterior, e assim por diante:

1) Datas Separadas: $D-2, D-1, D 0, D+1, D+2$;

2) Conjunto de datas após a intervenção: de $D 0$ a $D+1$ e $D 0$ a $D+2$;

3) Conjunto de datas antes e após a intervenção: de $D-1$ a $D+1$ e $D-2$ a $D+2$.

Esse procedimento foi feito para cada sub-período, assim como a série inteira, separados para as intervenções de compra e venda e também com a combinação de compras e vendas, esta sendo denominada de combinada. $\mathrm{O}$ objetivo dos diferentes testes foi a busca por maior robustez nos resultados na subseção anterior.

Considerando o período inteiro, tabela 8 do anexo, alterações no comportamento do câmbio são encontradas nas intervenções de compra, de venda e na série combinada. O período de destaque ocorre em D0 e no intervalo $[D 0 ; D+1]$, com significância a $1 \%$ e $10 \%$, respectivamente. Pode ser visto também um fenômeno de dissipação desse efeito após $D+1$, onde não é possível detectar alteração no comportamento do câmbio, um indicativo de que o efeito cambial é de curta duração, compatível com os resultados anteriores.

Em relação aos valores das medianas, há diferenças de sinais entre as amostras em todos os resultados significantes: tanto nas intervenções de venda como nas combinadas, as séries com as datas de intervenções apresentam medianas positivas enquanto nas séries sem as datas das intervenções as medianas são negativas. Já para as intervenções de compra, ocorre o oposto: medianas negativas nas séries com as datas de intervenções e medianas positivas nas séries sem as datas.

A análise segmentada por períodos não permite identificação de diferença significativa entre as séries no primeiro sub-período. Para o segundo, é observada significância de $5 \%$ no intervalo $[D-1 ; D+1]$ para as vendas, porém a proeminência é na direção de compras, que apresentam alteração no comportamento da mediana nos intervalos [D0;D+1], $[D 0 ; D+2],[D-1 ; D+1]$ e $[D-2 ; D+2]$. Nesse período as medianas continuaram a apresentar inversão de sinais.

Não foi possível realizar o teste para as intervenções de venda no terceiro subperíodo devido à baixa frequência de episódios. Na direção de compra, novamente há identificação de mudança no comportamento cambial, agora para as datas $D-1$, $D 0, D+1$ e $D+2$; todas significantes a $1 \%$, com exceção de $D-1$, significante a $5 \%$. Para o quarto sub-período, as datas $D-1, D 0$ e $D+1$ são significantes a $5 \%$, para intervenções de venda, indicando alteração no comportamento cambial. As atuações na direção de compra foram de baixa frequência nesse último subperíodo. 
As séries de intervenções também foram analisadas individualmente, através do teste de Wilcoxon para mediana igual a zero. Os intervalos significantes foram muito semelhantes aos resultados acima descritos, e por isso os seus resultados não foram reportados.

Em termos gerais, foi observado que as intervenções realizadas de forma contínua apresentam maior capacidade de afetar o comportamento cambial, tanto em reduzir a volatilidade como em afetar a sua direção. Este resultado é similar ao verificado por Araujo e Goldfajn (2004), mesmo que o poder de reduzir a volatilidade apenas tenha sido verificado quando controlaram o efeito da endogeneidade de efeito entre volatilidade e intervenções. Estes resultados mostram que os critérios identificam concentração de resultados significantes nas janelas de um a dois dias após as intervenções, e o teste de Mann-Whitney-Wilcoxon frequentemente demonstra dissipação já no segundo dia após as intervenções. Este resultado é compatível com o de Neely (2005), que encontrou indícios de que as intervenções têm efeito de curto prazo.

\section{Conclusão}

Neste artigo foram analisadas as intervenções cambiais realizadas por meio do mercado à vista, ocorridas entre 1999 e 2008, pela abordagem de estudo de eventos. Muitas vezes, essas intervenções podem ocorrer sem necessariamente haver uma busca primária por efeitos na taxa de câmbio, pois a real intenção por trás das intervenções cambiais frequentemente não é divulgada. Esta restrição faz com que a análise se atenha ao que pode ser observado de fato.

Uma conclusão inicial é que as intervenções realizadas de forma contínua (intervenções que não foram espaçadas por dias úteis) apresentam maior capacidade de afetar o comportamento do câmbio, tanto em reduzir a volatilidade como em afetar a sua direção, resultado que vai ao encontro do verificado no estudo de Araujo e Goldfajn (2004), que testam esse efeito através de modelo EGARCH com dummies. Esse resultado incita o debate sobre a publicidade das intervenções, porque intervenções feitas de forma contínua podem causar ajustes mais precisos nas expectativas dos agentes do mercado cambial, em comparação a intervenções pontuais. Uma extensão natural deste trabalho seria identificar a importância relativa de cada um dos canais de transmissão, dando ênfase ao canal das expectativas. Estudos que verificam o efeito de pronunciamentos (sem e com a contrapartida de intervenções reais), como o de Fratzscher (2005), podem ser replicados para o caso brasileiro, com o objetivo de averiguar a importância deste canal.

A divisão da análise dos critérios em janelas de diferentes durações indica que os efeitos da intervenção no câmbio, tanto na volatilidade como na direção cambial, são mais frequentes nas janelas imediatamente após as intervenções, de um a dois dias após as mesmas. O teste de Mann-Whitney-Wilcoxon também indica resultados similares. Estes resultados corroboram o estudo de Neely (2005), reafirmando o efeito de intervenções esterilizadas no curtíssimo prazo. Foi identificada redução de volatilidade para as intervenções a favor da maré, considerando-se o 
período na íntegra; já a segmentação da série através do MS-VAR permitiu também identificar redução de volatilidade nas intervenções de venda contra a maré do segundo sub-período, em que ocorreu a crise de confiança nas eleições presidenciais de 2002. Foi possível identificar redução de volatilidade para intervenções de compra a favor da maré no terceiro sub-período, marcado por uma tendência de apreciação, com atuações de compra pelo BACEN e Tesouro Nacional com objetivo deliberado de aumentar as reservas internacionais.

O critério de direção foi capaz de identificar, para a série inteira, reversão na direção cambial para as intervenções feitas contra a maré. A segmentação da série não permitiu uma clara identificação de um período de concentração de sucessos nesse critério, com exceção para as reversões obtidas com as intervenções de venda contra a maré no último sub-período, que faz referência à súbita depreciação do câmbio ao final de 2008.

A elaboração do critério de aceleração, em complemento aos outros critérios de Fatum e Hutchinson (2006), comentados acima, identificou uma tendência à obtenção de sucessos nas intervenções de compras a favor da maré. Isso é um indicativo de que o câmbio está mais propenso a responder a estímulos aceleracionistas na direção de depreciação da moeda local; este resultado pode ser complementar ao estudo de Meurer et alii (2007) de que depreciações ocorrem em movimentos mais rápidos que apreciações.

O efeito verificado das intervenções sobre a direção e a redução da volatilidade pode ser comparado com os resultados de diversos estudos internacionais, como sumarizado por Menkhoff (2010). Quanto ao efeito sobre os retornos, o efeito de curtíssimo prazo verificado (significativos até a janela de dois dias) estão de acordo com o verificado no referido survey.

No presente artigo, quando considerado o período inteiro, apenas nas intervenções de venda as janelas de mais longa duração (acima de cinco dias) apresentaram eficácia em reduzir a volatilidade. Para os demais casos o impacto apresentou-se significativo apenas no curtíssimo prazo (até dois dias). Isso difere, em parte, dos resultados do survey de Menkhoff (2010), que verifica que no curtíssimo prazo o efeito é de aceleração da volatilidade, decorrente do problema de endogeneidade, e que o efeito de redução da volatilidade ocorre com maior defasagem, o que também verificado para o caso brasileiro por Araujo e Goldfajn (2004). A questão que se coloca é qual o real papel da endogeneidade em verificações empíricas desta natureza e como contornar este problema. Estudos como o de Menkhoff (2010) e Chen et alii (2009) afirmam que a solução mais razoável é trabalhar com dados de alta frequência e, dada a indisponibilidade de séries desta natureza, propõem técnicas para extrapolação de dados diários, o que parece ser um caminho natural para a extensão de estudos em intervenções cambiais. 


\section{Referências}

Araujo, J. D. P. \& Goldfajn, I. (2004). Suavizando movimentos da taxa de câmbio ou adicionando volatilidade? Um estudo empírico sobre intervenções do banco central no mercado de câmbio. Dissertação de Mestrado em Economia, Pontifícia Universidade Católica do Rio de Janeiro.

Bacen - Banco Central do Brasil (2003-2007). Análise do mercado de câmbio. Disponível em http: //www. bacen.gov.br/?RELCAMBIO.

Bergin, P. (2004). Measuring the costs of exchange rate volatility. FRBSF Economic Letter, pages 1-4.

BIS (2005). Foreign exchange market intervention in emerging markets: Motives, techniques and implications. BIS Papers.

Chen, C., Watanabe, T., \& Yabu, T. (2009). A new method for identifying the effects of foreign exchange interventions. IMES Discussion Paper Series, n. 09-E-06, Institute for Monetary and Economic Studies.

Coppes, R. C. (1995). Are exchange rate changes normally distributed? Economics Letters, 47:117-121.

Disyatat, P. \& Galati, G. (2007). The effectiveness of foreign exchange intervention in emerging market countries: Evidence from the Czech koruna. Journal of International Money and Finance, 26:383-402.

Dominguez, K. \& Frankel, J. (1993). Does foreign exchange intervention matter? Disentangling the portfolio and expectations effects for the mark. American Economic Review, 83:1359-1369.

Dueker, M. \& Neely, C. J. (2007). Can markov switching models predict excess foreign exchange returns? Journal of Banking and Finance, 31:279-296.

Fatum, R. \& Hutchinson, M. (2003). Is sterilized foreign exchange intervention effective after all? An event study approach. Economic Journal, 117:390-411.

Fatum, R. \& Hutchinson, M. (2006). Effectiveness of official daily foreign exchange market intervention operations in Japan. Journal of International Money and Finance, 25:199-219.

Fratzscher, M. (2005). How successful are exchange rate communication and interventions? Evidence from time series and event-study approaches. ECB Working Paper 528, European Central Bank.

Gnabo, J.-Y., Mello, L., \& Moccero, D. (2008). Interdependencies between monetary policy and foreign exchange intervention under inflation targeting: The case of Brazil and the Czech Republic. Working Papers RP2008/95, World Institute for Development Economic Research (UNU-WIDER). 
Hamilton, J. D. (1989). A new approach to the economic analysis of nonstationary time series and the business cycle. Econometrica, 57:357-384.

Krolzig, H.-M. (1997). Markov Switching Vector Autoregressions: Modelling, Statistical Inference and Application to Business Cycle Analysis. Springer, Berlin.

Krolzig, H.-M. (2005). MSVAR OX Package 1.32a. Disponível em: http:// www.krolzig.co.uk/index.html?content=/msvar.html.

Lehman, E. L. (1988). Nonparametric Statistics: Statistical Methods Based on Ranks. McGraw Hill Textbooks, New York.

Menkhoff, L. (2010). High-frequency analysis of foreign exchange interventions: What do we learn? Journal of Economic Surveys, 24:85-112.

Meurer, R., Moura, G. S., \& Nunes, M. S. (2007). O vencimento da dívida pública cambial influencia a taxa de câmbio? Um estudo econométrico para o Brasil no périodo 2003-2004. Economia Aplicada, 11:55-72.

Neely, C. J. (2005). An analysis of recent studies of the effect of foreign exchange intervention. review. Federal Reserve Bank of St. Louis, 87:685-718.

Novaes, W. \& Oliveira, F. N. (2007). Interventions in the foreign exchange market: Effectiveness of derivatives and other instruments. Discussion Paper, n. 01, IBMEC Business School, Rio de Janeiro.

Obstfeld, M. (1990). The effectiveness of foreign-exchange intervention: Recent experience, 1985-1988. In Branson, W., Frenkel, J., \& Goldstein, M., editors, International Policy Coordination and Exchange Rate Fluctuations, pages 197246. University of Chicago Press, Chicago.

Sarno, L. \& Taylor, M. P. (2001). Official intervention in the foreign exchange market: Is it effective and, if so, how does it work? Journal of Economic Literature, 39:839-868.

Schwartz, A. J. (2004). The rise and fall of foreign exchange market intervention as a policy tool. Journal of Financial Services Research, 18:319-339.

Taylor, M. P. (2004). Is official exchange rate intervention effective? Economica, 71:1-11.

Wilcoxon, F. (1945). Individual comparisons by ranking methods. Biometrics Bulletin, 1:80-83. 


\section{Anexo}

Tabela A.1

Listagem dos eventos

\begin{tabular}{|c|c|c|c|}
\hline $\mathrm{n}$. & Data do Evento & Dias* & Interv.** \\
\hline 1 & $8 / 2 / 99$ & 1 & 215 \\
\hline 2 & $10 / 3 / 99-12 / 3 / 99$ & 3 & -870 \\
\hline 3 & $24 / 3 / 99-25 / 3 / 99$ & 2 & 453 \\
\hline 4 & $29 / 3 / 99-5 / 4 / 99$ & 4 & -262 \\
\hline 5 & $12 / 4 / 99-22 / 4 / 99$ & 8 & -1375 \\
\hline 6 & $11 / 5 / 99$ & 1 & 290 \\
\hline 7 & $11 / 10 / 99$ & 1 & -667 \\
\hline 8 & 27/12/99 & 1 & -1401 \\
\hline 9 & $3 / 1 / 00$ & 1 & 844 \\
\hline 10 & $6 / 1 / 00$ & 1 & 511 \\
\hline 11 & $22 / 11 / 00$ & 1 & 1978 \\
\hline 12 & $26 / 12 / 00$ & 1 & -1001 \\
\hline 13 & $3 / 1 / 01$ & 1 & 1011 \\
\hline 14 & $15 / 3 / 01$ & 1 & -311 \\
\hline 15 & $28 / 5 / 01$ & 1 & -249 \\
\hline 16 & $18 / 6 / 01$ & 1 & -445 \\
\hline 17 & $21 / 6 / 01$ & 1 & -219 \\
\hline 18 & $27 / 6 / 01$ & 1 & -649 \\
\hline 19 & $17 / 6 / 02$ & 1 & -437 \\
\hline 20 & $20 / 6 / 02$ & 1 & -241 \\
\hline 21 & $25 / 6 / 02$ & 1 & -321 \\
\hline 22 & $1 / 7 / 02$ & 1 & -303 \\
\hline 23 & $9 / 8 / 02$ & 1 & -257 \\
\hline 24 & $14 / 8 / 02$ & 1 & -210 \\
\hline 25 & $24 / 9 / 02$ & 1 & -219 \\
\hline 26 & $30 / 9 / 02$ & 1 & -232 \\
\hline 27 & $16 / 10 / 02$ & 1 & -229 \\
\hline 28 & $5 / 12 / 02$ & 1 & -452 \\
\hline 29 & $16 / 12 / 02$ & 1 & -207 \\
\hline 30 & $24 / 12 / 02$ & 1 & -461 \\
\hline 31 & $2 / 1 / 03$ & 1 & 386 \\
\hline 32 & $6 / 1 / 03$ & 1 & 226 \\
\hline 33 & $9 / 1 / 03$ & 1 & 390 \\
\hline 34 & $19 / 2 / 03-20 / 2 / 03$ & 2 & -449 \\
\hline 35 & $26 / 2 / 03$ & 1 & -353 \\
\hline 36 & $28 / 2 / 03$ & 1 & 358 \\
\hline 37 & $30 / 4 / 03$ & 1 & 508 \\
\hline 38 & $9 / 1 / 04$ & 1 & 224 \\
\hline 39 & $16 / 1 / 04-19 / 1 / 04$ & 2 & 667 \\
\hline 40 & $22 / 1 / 04-26 / 1 / 04$ & 3 & 964 \\
\hline 41 & $15 / 12 / 04$ & 1 & 204 \\
\hline 42 & $20 / 12 / 04-23 / 12 / 04$ & 4 & 1455 \\
\hline 43 & $27 / 12 / 04$ & 1 & 519 \\
\hline 44 & $4 / 1 / 05$ & 1 & 242 \\
\hline 45 & $10 / 1 / 05$ & 1 & 328 \\
\hline 46 & $14 / 1 / 05$ & 1 & 248 \\
\hline 47 & $24 / 1 / 05$ & 1 & 300 \\
\hline 48 & $26 / 1 / 05$ & 1 & 544 \\
\hline 49 & $1 / 2 / 05$ & 1 & 201 \\
\hline 50 & $4 / 2 / 05$ & 1 & 377 \\
\hline 51 & $10 / 2 / 05$ & 1 & 587 \\
\hline 52 & $14 / 2 / 05-15 / 2 / 05$ & 2 & 1113 \\
\hline 53 & $21 / 2 / 05$ & 1 & 363 \\
\hline 54 & $23 / 2 / 05$ & 1 & 330 \\
\hline 55 & $25 / 2 / 05$ & 1 & 1204 \\
\hline 56 & $1 / 3 / 05-2 / 3 / 05$ & 2 & 708 \\
\hline
\end{tabular}


Meurer, R., Teixeira, F., Tomazzia, E.

\begin{tabular}{|c|c|c|c|}
\hline n. & Data do Evento & Dias* & Interv.** \\
\hline 57 & $7 / 3 / 05-9 / 3 / 05$ & 3 & 1233 \\
\hline 58 & $16 / 3 / 05$ & 1 & 499 \\
\hline 59 & $4 / 10 / 05$ & 1 & 286 \\
\hline 60 & $10 / 10 / 05$ & 1 & 479 \\
\hline 61 & $14 / 10 / 05-17 / 10 / 05$ & 2 & 488 \\
\hline 62 & $20 / 10 / 05$ & 1 & 781 \\
\hline 63 & $26 / 10 / 05-28 / 10 / 05$ & 3 & 766 \\
\hline 64 & $1 / 11 / 05-8 / 11 / 05$ & 5 & 1676 \\
\hline 65 & $10 / 11 / 05-11 / 11 / 05$ & 2 & 674 \\
\hline 66 & $16 / 11 / 05-17 / 11 / 05$ & 2 & 589 \\
\hline 67 & $28 / 11 / 05-29 / 11 / 05$ & 2 & 701 \\
\hline 68 & $1 / 12 / 05$ & 1 & 371 \\
\hline 69 & $5 / 12 / 05$ & 1 & 593 \\
\hline 70 & $13 / 12 / 05$ & 1 & 494 \\
\hline 71 & $15 / 12 / 05$ & 1 & 296 \\
\hline 72 & $20 / 12 / 05-21 / 12 / 05$ & 2 & 674 \\
\hline 73 & $23 / 12 / 05-26 / 12 / 05$ & 2 & 532 \\
\hline 74 & $4 / 1 / 06$ & 1 & 257 \\
\hline 75 & $10 / 1 / 06$ & 1 & 248 \\
\hline 76 & $16 / 1 / 06$ & 1 & 249 \\
\hline 77 & 26/1/06 & 1 & 293 \\
\hline 78 & $6 / 2 / 06$ & 1 & 213 \\
\hline 79 & $8 / 2 / 06$ & 1 & 234 \\
\hline 80 & $17 / 2 / 06$ & 1 & 472 \\
\hline 81 & $24 / 2 / 06-1 / 3 / 06$ & 2 & 759 \\
\hline 82 & $10 / 3 / 06$ & 1 & 282 \\
\hline 83 & $14 / 3 / 06-15 / 3 / 06$ & 2 & 539 \\
\hline 84 & $22 / 3 / 06$ & 1 & 436 \\
\hline 85 & $11 / 4 / 06$ & 1 & 241 \\
\hline 86 & $13 / 4 / 06$ & 1 & 244 \\
\hline 87 & $18 / 4 / 06$ & 1 & 217 \\
\hline 88 & $24 / 4 / 06$ & 1 & 230 \\
\hline 89 & $2 / 5 / 06-10 / 5 / 06$ & 7 & 3842 \\
\hline 90 & $10 / 7 / 06-12 / 7 / 06$ & 3 & 1331 \\
\hline 91 & $14 / 7 / 06$ & 1 & 429 \\
\hline 92 & $18 / 7 / 06-19 / 7 / 06$ & 2 & 1147 \\
\hline 93 & $24 / 7 / 06$ & 1 & 458 \\
\hline 94 & $26 / 7 / 06-31 / 7 / 06$ & 4 & 1172 \\
\hline 95 & $2 / 8 / 06$ & 1 & 601 \\
\hline 96 & $7 / 8 / 06$ & 1 & 384 \\
\hline 97 & $9 / 8 / 06-15 / 8 / 06$ & 5 & 1422 \\
\hline 98 & $17 / 8 / 06$ & 1 & 299 \\
\hline 99 & $21 / 8 / 06$ & 1 & 233 \\
\hline 100 & $12 / 9 / 06-13 / 9 / 06$ & 2 & 553 \\
\hline 101 & $19 / 9 / 06$ & 1 & 239 \\
\hline 102 & $4 / 10 / 06$ & 1 & 349 \\
\hline 103 & $10 / 10 / 06-11 / 10 / 06$ & 2 & 633 \\
\hline 104 & $17 / 10 / 06-19 / 10 / 06$ & 3 & 1055 \\
\hline 105 & $23 / 10 / 06-24 / 10 / 06$ & 2 & 515 \\
\hline 106 & $26 / 10 / 06-31 / 10 / 06$ & 4 & 1552 \\
\hline 107 & $6 / 11 / 06$ & 1 & 234 \\
\hline 108 & $14 / 11 / 06$ & 1 & 340 \\
\hline 109 & $24 / 11 / 06$ & 1 & 319 \\
\hline 110 & $5 / 12 / 06$ & 1 & 208 \\
\hline 111 & $7 / 12 / 06$ & 1 & 239 \\
\hline 112 & $11 / 12 / 06$ & 1 & 263 \\
\hline 113 & $13 / 12 / 06-14 / 12 / 06$ & 2 & 460 \\
\hline 114 & $26 / 12 / 06$ & 1 & 420 \\
\hline 115 & $28 / 12 / 06$ & 1 & 504 \\
\hline 116 & $2 / 1 / 07$ & 1 & 440 \\
\hline 117 & $12 / 1 / 07-15 / 1 / 07$ & 2 & 852 \\
\hline 118 & $17 / 1 / 07-22 / 1 / 07$ & 4 & 1337 \\
\hline
\end{tabular}




\begin{tabular}{|c|c|c|c|}
\hline $\mathrm{n}$. & Data do Evento & Dias* & Interv.** \\
\hline 119 & $24 / 1 / 07$ & 1 & 362 \\
\hline 120 & $26 / 1 / 07-2 / 2 / 07$ & 6 & 2018 \\
\hline 121 & $6 / 2 / 07-9 / 2 / 07$ & 4 & 2182 \\
\hline 122 & $13 / 2 / 07-12 / 3 / 07$ & 18 & 9878 \\
\hline 123 & $14 / 3 / 07$ & 1 & 241 \\
\hline 124 & 19/3/07-22/3/07 & 4 & 1875 \\
\hline 125 & 26/3/07 & 1 & 395 \\
\hline 126 & $2 / 4 / 07-23 / 5 / 07$ & 36 & 23281 \\
\hline 127 & $25 / 5 / 07-28 / 5 / 07$ & 2 & 1865 \\
\hline 128 & $30 / 5 / 07-5 / 6 / 07$ & 5 & 3809 \\
\hline 129 & $8 / 6 / 07-11 / 6 / 07$ & 2 & 1236 \\
\hline 130 & $13 / 6 / 07-18 / 6 / 07$ & 5 & 1913 \\
\hline 131 & 20/6/07 - 27/6/07 & 6 & 1938 \\
\hline 132 & $29 / 6 / 07$ & 1 & 204 \\
\hline 133 & $3 / 7 / 07-5 / 7 / 07$ & 3 & 1457 \\
\hline 134 & $10 / 7 / 07-12 / 7 / 07$ & 3 & 2039 \\
\hline 135 & $16 / 7 / 07-17 / 7 / 07$ & 2 & 657 \\
\hline 136 & 19/7/07 & 1 & 278 \\
\hline 137 & $23 / 7 / 07-24 / 07 / 07$ & 2 & 1011 \\
\hline 138 & $27 / 7 / 07-30 / 7 / 07$ & 2 & 860 \\
\hline 139 & $2 / 8 / 07$ & 1 & 637 \\
\hline 140 & $7 / 8 / 07-8 / 8 / 07$ & 2 & 1062 \\
\hline 141 & $13 / 8 / 07$ & 1 & 306 \\
\hline 142 & $11 / 10 / 07$ & 1 & 209 \\
\hline 143 & $18 / 10 / 07-19 / 10 / 07$ & 2 & 1007 \\
\hline 144 & $23 / 10 / 07$ & 1 & 260 \\
\hline 145 & $26 / 10 / 07-31 / 10 / 07$ & 4 & 2789 \\
\hline 146 & $6 / 11 / 07$ & 1 & 951 \\
\hline 147 & $12 / 11 / 07$ & 1 & 475 \\
\hline 148 & $14 / 11 / 07$ & 1 & 329 \\
\hline 149 & $22 / 11 / 07-23 / 11 / 07$ & 2 & 831 \\
\hline 150 & $28 / 11 / 07$ & 1 & 272 \\
\hline 151 & $30 / 11 / 07$ & 1 & 622 \\
\hline 152 & $5 / 12 / 07$ & 1 & 294 \\
\hline 153 & $11 / 12 / 07$ & 1 & 257 \\
\hline 154 & $21 / 12 / 07$ & 1 & 212 \\
\hline 155 & $28 / 12 / 07$ & 1 & 403 \\
\hline 156 & $3 / 1 / 08$ & 1 & 226 \\
\hline 157 & $8 / 1 / 08$ & 1 & 324 \\
\hline 158 & $21 / 2 / 08$ & 1 & 405 \\
\hline 159 & $25 / 2 / 08-27 / 2 / 08$ & 3 & 1221 \\
\hline 160 & $13 / 3 / 08$ & 1 & 222 \\
\hline 161 & $28 / 3 / 08$ & 1 & 270 \\
\hline 162 & $9 / 4 / 08-10 / 4 / 08$ & 2 & 617 \\
\hline 163 & $15 / 4 / 08$ & 1 & 279 \\
\hline 164 & $17 / 4 / 08$ & 1 & 387 \\
\hline 165 & $24 / 4 / 08-25 / 4 / 08$ & 2 & 641 \\
\hline 166 & $29 / 4 / 08$ & 1 & 276 \\
\hline 167 & $15 / 5 / 08$ & 1 & 306 \\
\hline 168 & $30 / 5 / 08$ & 1 & 340 \\
\hline 169 & $6 / 6 / 08-9 / 6 / 08$ & 2 & 550 \\
\hline 170 & $1 / 7 / 08$ & 1 & 214 \\
\hline 171 & $4 / 7 / 08$ & 1 & 284 \\
\hline 172 & $1 / 8 / 08$ & 1 & 230 \\
\hline 173 & $1 / 9 / 08$ & 1 & 200 \\
\hline 174 & 19/9/08 & 1 & -498 \\
\hline 175 & 24/9/08 & 1 & 599 \\
\hline 176 & 26/9/08 & 1 & -498 \\
\hline 177 & $7 / 10 / 08-8 / 10 / 08$ & 2 & -2047 \\
\hline 178 & $10 / 10 / 08-13 / 10 / 08$ & 2 & -948 \\
\hline 179 & $15 / 10 / 08-16 / 10 / 08$ & 2 & -2659 \\
\hline 180 & $20 / 10 / 08-27 / 10 / 08$ & 6 & -2472 \\
\hline 181 & $30 / 10 / 08$ & 1 & -865 \\
\hline
\end{tabular}


Tabela A.2

Critério de volatilidade

\begin{tabular}{|c|c|c|c|c|c|c|c|c|c|c|c|c|c|c|c|}
\hline \multicolumn{16}{|c|}{ Período Inteiro - 05/01/1999 - 31/12/2008 - Todas as Intervenções } \\
\hline & \multicolumn{3}{|c|}{ D1 } & \multicolumn{3}{|c|}{ D2 } & \multicolumn{3}{|c|}{ D5 } & \multicolumn{3}{|c|}{ D10 } & \multicolumn{3}{|c|}{ D20 } \\
\hline & $\mathrm{n}$. & s. & $\bar{P}$ & $\mathrm{n}$. & s. & $\mathrm{P}$ & $\mathrm{n}$. & s. & $\mathrm{P}$ & n. & s. & $\mathrm{P}$ & n. & s. & $\overline{\mathrm{P}}$ \\
\hline Compras & 150 & 71 & $71,61 \%$ & 150 & 75 & $46,75 \%$ & 150 & 71 & $71,61 \%$ & 150 & 68 & $85,58 \%$ & 150 & 59 & $99,44 \%$ \\
\hline a favor & 81 & 46 & $9,10 \% *$ & 65 & 32 & $50,00 \%$ & 58 & 29 & $44,78 \%$ & 53 & 34 & $1,35 \%$ ** & 40 & 22 & $21,48 \%$ \\
\hline contra & 69 & 25 & $98,53 \%$ & 85 & 43 & $41,42 \%$ & 92 & 42 & $76,71 \%$ & 97 & 34 & $99,79 \%$ & 110 & 37 & $99,96 \%$ \\
\hline Vendas & 41 & 23 & $17,44 \%$ & 41 & 16 & $89,45 \%$ & 41 & 17 & $82,56 \%$ & 41 & 19 & $62,24 \%$ & 41 & 25 & $5,86 \% *$ \\
\hline a favor & 20 & 14 & $2,07 \%$ ** & 23 & 10 & $66,12 \%$ & 17 & 9 & $31,45 \%$ & 13 & 8 & $13,34 \%$ & 8 & 6 & $3,52 \% * *$ \\
\hline contra & 21 & 9 & $66,82 \%$ & 18 & 6 & $88,11 \%$ & 24 & 8 & $92,42 \%$ & 28 & 11 & $82,75 \%$ & 33 & 19 & $14,81 \%$ \\
\hline Int. a favor & 101 & 60 & $2,30 \%$ **** & 88 & 42 & $62,53 \%$ & 75 & 38 & $40,88 \%$ & 66 & 42 & $0,93 \% * * *$ & 48 & 28 & $9,67 \% *$ \\
\hline Int. & 90 & 34 & $98,68 \%$ & 103 & 49 & $65,32 \%$ & 116 & 50 & $91,83 \%$ & 125 & 45 & $99,89 \%$ & 143 & 56 & $99,41 \%$ \\
\hline Totol & 191 & 94 & $55,75 \%$ & 191 & 91 & $71,86 \%$ & 191 & 88 & $84,45 \%$ & 191 & 87 & $87,65 \%$ & 191 & 84 & $94,44 \%$ \\
\hline \multicolumn{16}{|c|}{ Período Inteiro - 05/01/1999 - 31/12/2008 - Apenas as Intervenções Contínuas } \\
\hline & n. & s. & $\bar{P}$ & $\mathrm{n}$. & s. & $\bar{P}$ & $\mathrm{n}$. & s. & $\mathrm{P}$ & n. & s. & $\mathrm{P}$ & $\mathrm{n}$. & s. & $\bar{P}$ \\
\hline Com & 54 & 27 & $44,60 \%$ & 54 & 25 & $65,83 \%$ & 54 & 27 & $44,60 \%$ & 54 & 24 & $75,17 \%$ & 54 & 18 & $99,01 \%$ \\
\hline & 26 & 19 & $0,47 \%$ **** & 25 & 12 & $50,00 \%$ & 25 & 14 & $21,22 \%$ & 21 & 11 & $33,18 \%$ & 10 & 4 & $62,30 \%$ \\
\hline cor & 28 & 8 & $98,22 \%$ & 29 & 13 & $64,45 \%$ & 29 & 13 & $64,45 \%$ & 33 & 13 & $85,19 \%$ & 44 & 14 & $98,87 \%$ \\
\hline Vendas & 13 & 8 & $13,34 \%$ & 13 & 7 & $29,05 \%$ & 13 & 9 & $4,61 \% * *$ & 13 & 9 & $4,61 \%$ ** & 13 & 12 & $0,01 \% * * *$ \\
\hline & 9 & 8 & $0,20 \% * * *$ & 8 & 3 & $63,67 \%$ & 6 & 5 & $1,56 \% * *$ & 4 & 3 & $6,25 \% * *$ & 3 & 3 & $0,00 \% * * *$ \\
\hline cor & 4 & 0 & $3,75 \%$ & 5 & 4 & $3,13 \% * *$ & 7 & 4 & $22,66 \%$ & 9 & 6 & $8,98 \% * *$ & 10 & 9 & $0,10 \% * * *$ \\
\hline vor & 35 & 27 & $0,03 \% * * *$ & 33 & 15 & 63 & 31 & 19 & $7,48 \% * *$ & 25 & 14 & $\%$ & 13 & 7 & $29,05 \%$ \\
\hline & 32 & 8 & $99,65 \%$ & 34 & 17 & 43,2 & 36 & 17 & $56,60 \%$ & 42 & 19 & $67,80 \%$ & 54 & 23 & $82,96 \%$ \\
\hline & 67 & 35 & $31,27 \%$ & 67 & 32 & $59,64 \%$ & 67 & 36 & $23,19 \%$ & 67 & 33 & $50,00 \%$ & 67 & 30 & $76,81 \%$ \\
\hline \multicolumn{16}{|c|}{ Subperíodo 2 - 26/04/2002 - 11/08/2003 - Todas as Intervenções } \\
\hline & $\mathrm{n}$. & s. & $\mathrm{P}$ & $\mathrm{n}$. & s. & $\mathrm{P}$ & $\mathrm{n}$. & s. & $\mathrm{P}$ & n. & s. & $\mathrm{P}$ & n. & s. & $\mathrm{P}$ \\
\hline ndas & 14 & 9 & $8,98 \% *$ & 14 & 5 & $78,80 \%$ & 14 & 5 & $78,80 \%$ & 14 & 6 & $60,47 \%$ & 14 & 7 & $39,53 \%$ \\
\hline & 5 & 3 & $18,75 \%$ & 8 & 4 & $36,33 \%$ & 4 & 2 & $31,25 \%$ & 3 & 3 & $0,00 \% * * *$ & 2 & 2 & $0,00 \% * * *$ \\
\hline con & 9 & 6 & $3 \% *$ & 6 & 1 & $89,06 \%$ & 10 & 3 & $82,81 \%$ & 11 & 3 & $88,67 \%$ & 12 & 5 & $61,28 \%$ \\
\hline & 7 & 4 & $\%$ & 8 & 4 & 36 , & 5 & 2 & 50, & 3 & 3 & $0,00 \%$ *** & 3 & 3 & $0,00 \%$ *** \\
\hline Int. $\mathrm{c}$ & 12 & 6 & $38,72 \%$ & 11 & 3 & $88,67 \%$ & 14 & 5 & $78,80 \%$ & 16 & 5 & $89,49 \%$ & 16 & 5 & $89,49 \%$ \\
\hline Total & 19 & 10 & $32,38 \%$ & 19 & 7 & $82,04 \%$ & 19 & 7 & $82,04 \%$ & 19 & 8 & $67,62 \%$ & 19 & 8 & $67,62 \%$ \\
\hline \multicolumn{16}{|c|}{ Subperíodo 3 - 12/08/2003 - 08/09/2008 - Todas as Intervenções } \\
\hline & n. & s. & $\mathrm{P}$ & $\mathrm{n}$. & s. & $\mathrm{P}$ & n. & s. & $\bar{P}$ & n. & s. & $\bar{P}$ & n. & s. & $\bar{P}$ \\
\hline om & 136 & 66 & $60,14 \%$ & 136 & 69 & $39,86 \%$ & 136 & 62 & $82,72 \%$ & 136 & 60 & $90,09 \%$ & 136 & 51 & $99,78 \%$ \\
\hline & 74 & 43 & $6,51 \% *$ & 62 & 31 & $44,95 \%$ & 56 & 28 & $44,69 \%$ & 49 & 31 & $2,22 \% * *$ & 35 & 18 & $36,79 \%$ \\
\hline & 62 & 23 & & 74 & 38 & $36,38 \%$ & 80 & 34 & $89,07 \%$ & 87 & 29 & $99,88 \%$ & 101 & 33 & $99,97 \%$ \\
\hline a favor & 74 & 43 & $6,51 \% *$ & 62 & 31 & $44,95 \%$ & 56 & 28 & $44,69 \%$ & 49 & 31 & $2,22 \% * *$ & 35 & 18 & $36,79 \%$ \\
\hline $\mathrm{ra}$ & 62 & 23 & $97,21 \%$ & 74 & 38 & $36,38 \%$ & 80 & 34 & $89,07 \%$ & 87 & 29 & $99,88 \%$ & 101 & 33 & $99,97 \%$ \\
\hline Total & 136 & 66 & $60,14 \%$ & 136 & 69 & $39,86 \%$ & 136 & 62 & $82,72 \%$ & 136 & 60 & $90,09 \%$ & 136 & 51 & $99,78 \%$ \\
\hline \multicolumn{16}{|c|}{ Subperíodo 4 - 09/09/2008 - 31/12/2008 - Todas as Intervenções } \\
\hline & $\mathrm{n}$. & s. & $\mathrm{P}$ & n. & s. & $\mathrm{P}$ & $\mathrm{n}$. & s. & $\mathrm{P}$ & n. & s. & $\mathrm{P}$ & $\mathrm{n}$. & s. & $\mathrm{P}$ \\
\hline Vendas & 16 & 9 & $22,72 \%$ & 16 & 8 & $40,18 \%$ & 16 & 8 & $40,18 \%$ & 16 & 9 & $22,72 \%$ & 16 & 13 & $0,21 \%$ ** \\
\hline a favor & 10 & 8 & $1,07 \%$ *** & 8 & 3 & $63,67 \%$ & 7 & 4 & $22,66 \%$ & 4 & 3 & $6,25 \% *$ & 1 & 1 & $0,00 \% * * *$ \\
\hline cor & 6 & 1 & $89,06 \%$ & 8 & 5 & $14,45 \%$ & 9 & 4 & $50,00 \%$ & 12 & 6 & $38,72 \%$ & 15 & 12 & $0,37 \% * * *$ \\
\hline Int. a favor & 12 & 9 & $1,93 \%$ ** & 8 & 3 & $63,67 \%$ & 7 & 4 & $22,66 \%$ & 6 & 4 & $10,94 \%$ & 3 & 2 & $12,50 \%$ \\
\hline Int. contra & 6 & 1 & $89,06 \%$ & 10 & 7 & $5,47 \% *$ & 11 & 5 & $50,00 \%$ & 12 & 6 & $38,72 \%$ & 15 & 12 & $0,37 \% * * *$ \\
\hline Total & 18 & 10 & $24,03 \%$ & 18 & 10 & $24,03 \%$ & 18 & 9 & $40,73 \%$ & 18 & 10 & $24,03 \%$ & 18 & 14 & $0,38 \% * * *$ \\
\hline
\end{tabular}

com probabilidade de $50 \%$. 
Tabela A.3

Critério de direção

\begin{tabular}{|c|c|c|c|c|c|c|c|c|c|c|c|c|c|c|c|}
\hline \multicolumn{16}{|c|}{ Período Inteiro - 05/01/1999 - 31/12/2008 - Todas as Intervenções } \\
\hline & \multicolumn{3}{|c|}{ D1 } & \multicolumn{3}{|c|}{ D2 } & \multicolumn{3}{|c|}{ D5 } & \multicolumn{3}{|c|}{ D10 } & \multicolumn{3}{|c|}{$\mathrm{D} 20$} \\
\hline & $\mathrm{n}$. & s. & $\mathrm{P}$ & n. & s. & $\mathrm{P}$ & n. & s. & $\mathrm{P}$ & n. & $\mathrm{s.}$ & $\mathrm{P}$ & n. & s. & $\mathrm{P}$ \\
\hline Compras & 150 & 81 & $14,42 \%$ & 150 & 81 & $14,42 \%$ & 150 & 68 & $85,58 \%$ & 150 & 77 & $34,16 \%$ & 150 & 67 & $88,97 \%$ \\
\hline Compra a favor & 81 & 45 & $13,32 \%$ & 65 & 35 & $22,85 \%$ & 58 & 29 & $44,78 \%$ & 53 & 28 & $29,16 \%$ & 40 & 11 & $99,68 \%$ \\
\hline Compra contra & 69 & 36 & $31,52 \%$ & 85 & 46 & $19,28 \%$ & 92 & 39 & $91,25 \%$ & 97 & 49 & $41,96 \%$ & 110 & 56 & $38,75 \%$ \\
\hline Vendas & 41 & 17 & $82,56 \%$ & 41 & 21 & $37,76 \%$ & 41 & 21 & $37,76 \%$ & 41 & 21 & $37,76 \%$ & 41 & 21 & $37,76 \%$ \\
\hline Venda a favor & 20 & 8 & $74,83 \%$ & 23 & 11 & $50,00 \%$ & 17 & 7 & $68,55 \%$ & 13 & 8 & $13,34 \%$ & 8 & 5 & $14,45 \%$ \\
\hline Venda contra & 21 & 9 & $66,82 \%$ & 18 & 10 & $24,03 \%$ & 24 & 14 & $15,37 \%$ & 28 & 13 & $57,47 \%$ & 33 & 16 & $50,00 \%$ \\
\hline Interv. a favor & 101 & 53 & $27,54 \%$ & 88 & 46 & $29,71 \%$ & 75 & 36 & $59,12 \%$ & 66 & 36 & $19,45 \%$ & 48 & 16 & $98,53 \%$ \\
\hline Interv. contra & 90 & 45 & $45,81 \%$ & 103 & 56 & $16,22 \%$ & 116 & 53 & $79,83 \%$ & 125 & 62 & $50,00 \%$ & 143 & 72 & $43,36 \%$ \\
\hline Total & 191 & 98 & $33,21 \%$ & 191 & 102 & $15,55 \%$ & 191 & 89 & $80,74 \%$ & 191 & 98 & $33,21 \%$ & 191 & 88 & $84,45 \%$ \\
\hline \multicolumn{16}{|c|}{ Período Inteiro - 05/01/1999 - 31/12/2008 - Intervenções Contínuas } \\
\hline & $\mathrm{n}$. & s. & $\mathrm{P}$ & n. & s. & $\mathrm{P}$ & $\mathrm{n}$. & s. & $\mathrm{P}$ & n. & s. & $\mathrm{P}$ & n. & s. & $\mathrm{P}$ \\
\hline Compras & 54 & 35 & $0,99 \% * * *$ & 54 & 31 & $11,02 \%$ & 54 & 26 & $55,40 \%$ & 54 & 29 & $24,83 \%$ & 54 & 27 & $44,60 \%$ \\
\hline Compra a favor & 26 & 19 & $0,47 \% * * *$ & 25 & 13 & $34,50 \%$ & 25 & 14 & $21,22 \%$ & 21 & 12 & $19,17 \%$ & 10 & 2 & $94,53 \%$ \\
\hline Compra contra & 28 & 16 & $17,25 \%$ & 29 & 18 & $6,80 \% *$ & 29 & 12 & $77,09 \%$ & 33 & 17 & $36,42 \%$ & 44 & 25 & $14,56 \%$ \\
\hline Vendas & 13 & 7 & $29,05 \%$ & 13 & 9 & $4,61 \%$ ** & 13 & 9 & $4,61 \%$ *** & 13 & 8 & $13,34 \%$ & 13 & 9 & $4,61 \%$ ** \\
\hline Venda a favor & 9 & 5 & $25,39 \%$ & 8 & 5 & $14,45 \%$ & 6 & 4 & $10,94 \%$ & 4 & 3 & $6,25 \% *$ & 3 & 2 & $12,50 \%$ \\
\hline Venda contra & 4 & 2 & $31,25 \%$ & 5 & 4 & $3,13 \% * *$ & 7 & 5 & $6,25 \% *$ & 9 & 5 & $25,39 \%$ & 10 & 7 & $5,47 \% *$ \\
\hline Interv. a favor & 35 & 24 & $0,83 \%$ **** & 33 & 18 & $24,34 \%$ & 31 & 18 & $14,05 \%$ & 25 & 15 & $11,48 \%$ & 13 & 4 & $86,66 \%$ \\
\hline Interv. contra & 32 & 18 & $18,85 \%$ & 34 & 22 & $2,88 \% * *$ & 36 & 17 & $56,60 \%$ & 42 & 22 & $32,20 \%$ & 54 & 32 & $6,68 \% *$ \\
\hline Total & 67 & 42 & $1,36 \% * *$ & 67 & 40 & $4,32 \% * *$ & 67 & 35 & $31,27 \%$ & 67 & 37 & $16,42 \%$ & 67 & 36 & $23,19 \%$ \\
\hline \multicolumn{16}{|c|}{ Subperiodo 1 - 05/01/1999-25/04/2002 - Todas as Intervenções } \\
\hline & n. & s. & $\mathrm{P}$ & n. & s. & $\mathrm{P}$ & n. & s. & $\mathrm{P}$ & n. & s. & $\mathrm{P}$ & n. & s. & $\mathrm{P}$ \\
\hline Compras & 7 & 4 & $22,66 \%$ & 7 & 5 & $6,25 \%$ * & 7 & 5 & $6,25 \% *$ & 7 & 4 & $22,66 \%$ & 7 & 5 & $6,25 \% *$ \\
\hline Compra a favor & 3 & 2 & $12,50 \%$ & 3 & 1 & $50,00 \%$ & 1 & 0 & $50,00 \%$ & 2 & 1 & $25,00 \%$ & 2 & 2 & $0,00 \% * * *$ \\
\hline Compra contra & 4 & 2 & $31,25 \%$ & 4 & 4 & $0,00 \%$ *** & 6 & 5 & $1,56 \% * *$ & 5 & 3 & $18,75 \%$ & 5 & 3 & $18,75 \%$ \\
\hline $\begin{array}{l}\text { Vendas } \\
\text {. }\end{array}$ & 11 & 4 & $72,56 \%$ & 11 & 6 & $27,44 \%$ & 11 & 7 & $11,33 \%$ & 11 & 6 & $27,44 \%$ & 11 & 6 & $27,44 \%$ \\
\hline Venda : & 5 & 2 & $50,00 \%$ & 7 & 4 & $22,66 \%$ & 6 & 4 & $10,94 \%$ & 6 & 5 & $1,56 \% * *$ & 5 & 3 & $18,75 \%$ \\
\hline Venda contra & 6 & 2 & $65,63 \%$ & 4 & 2 & $31,25 \%$ & 5 & 3 & $18,75 \%$ & 5 & 1 & $81,25 \%$ & 6 & 3 & $34,38 \%$ \\
\hline Interv. a favor & 8 & 4 & $36,33 \%$ & 10 & 5 & $37,70 \%$ & 7 & 4 & $22,66 \%$ & 8 & 6 & $3,52 \%$ *** & 7 & 5 & $6,25 \% *$ \\
\hline Interv. contra & 10 & 4 & $62,30 \%$ & 8 & 6 & $3,52 \% * *$ & 11 & 8 & $3,27 \%$ & 10 & 4 & $62,30 \%$ & 11 & 6 & $27,44 \%$ \\
\hline Total & 18 & 8 & $59,27 \%$ & 18 & 11 & $11,89 \%$ & 18 & 12 & $4,81 \% * *$ & 18 & 10 & $24,03 \%$ & 18 & 11 & $11,89 \%$ \\
\hline \multicolumn{16}{|c|}{ Subperíodo 3 - 12/08/2003 - 08/09/2008 - Todas as Intervenções } \\
\hline & n. & s. & $\mathrm{P}$ & n. & s. & $\mathrm{P}$ & n. & s. & $\mathrm{P}$ & n. & s. & $\mathrm{P}$ & n. & S. & $\mathrm{P}$ \\
\hline Compras & 136 & 75 & $9,91 \% *$ & 136 & 73 & $17,28 \%$ & 136 & 60 & $90,09 \%$ & 136 & 69 & $39,86 \%$ & 136 & 57 & $96,43 \%$ \\
\hline Compra a favor & 74 & 42 & $10,03 \%$ & 62 & 34 & $18,71 \%$ & 56 & 29 & $34,44 \%$ & 49 & 26 & $28,41 \%$ & 35 & 8 & $99,91 \%$ \\
\hline Compra contra & 62 & 33 & $26,29 \%$ & 74 & 39 & $28,07 \%$ & 80 & 31 & $97,17 \%$ & 87 & 43 & $50,00 \%$ & 101 & 49 & $57,88 \%$ \\
\hline Interv. a favor & 74 & 42 & $10,03 \%$ & 62 & 34 & $18,71 \%$ & 56 & 29 & $34,44 \%$ & 49 & 26 & $28,41 \%$ & 35 & 8 & $99,91 \%$ \\
\hline Interv. contra & 62 & 33 & $26,29 \%$ & 74 & 39 & $28,07 \%$ & 80 & 31 & $97,17 \%$ & 87 & 43 & $50,00 \%$ & 101 & 49 & $57,88 \%$ \\
\hline Total & 136 & 75 & $9,91 \% *$ & 136 & 73 & $17,28 \%$ & 136 & 60 & $90,09 \%$ & 136 & 69 & $39,86 \%$ & 136 & 57 & $96,43 \%$ \\
\hline \multicolumn{16}{|c|}{ Subperíodo $4-09 / 09 / 2008-31 / 12 / 2008$ - Todas as Intervenções } \\
\hline & $\mathrm{n}$. & s. & $\mathrm{P}$ & $\mathrm{n}$. & s. & $\mathrm{P}$ & $\mathrm{n}$. & s. & $\mathrm{P}$ & n. & s. & $\mathrm{P}$ & n. & s. & $\mathrm{P}$ \\
\hline Vendas & 16 & 9 & $22,72 \%$ & 16 & 10 & $10,51 \%$ & 16 & 8 & $40,18 \%$ & 16 & 6 & $77,28 \%$ & 16 & 7 & $59,82 \%$ \\
\hline Venda a favor & 10 & 5 & $37,70 \%$ & 8 & 4 & $36,33 \%$ & 7 & 2 & $77,34 \%$ & 4 & 1 & $68,75 \%$ & 1 & 0 & $50,00 \%$ \\
\hline Venda contra & 6 & 4 & $10,94 \%$ & 8 & 6 & $3,52 \% * *$ & 9 & 6 & $8,98 \% *$ & 12 & 5 & $61,28 \%$ & 15 & 7 & $50,00 \%$ \\
\hline Interv. a favor & 12 & 5 & $61,28 \%$ & 8 & 4 & $36,33 \%$ & 7 & 2 & $77,34 \%$ & 6 & 2 & $65,63 \%$ & 3 & 1 & $50,00 \%$ \\
\hline Interv. contra & 6 & 4 & $10,94 \%$ & 10 & 8 & $1,07 \% * *$ & 11 & 8 & $3,27 \% * *$ & 12 & 5 & $61,28 \%$ & 15 & 7 & $50,00 \%$ \\
\hline Total & 18 & 9 & $40,73 \%$ & 18 & 12 & $4,81 \% * *$ & 18 & 10 & $24,03 \%$ & 18 & 7 & $75,97 \%$ & 18 & 8 & $59,27 \%$ \\
\hline
\end{tabular}

com probabilidade de $50 \%$ 
Tabela A.4

Critério de suavização e aceleração

\begin{tabular}{|c|c|c|c|c|c|c|c|c|c|c|c|c|}
\hline \multicolumn{13}{|c|}{ Período Inteiro - 05/01/1999 - 31/12/2008 - Todas as Intervenções } \\
\hline & \multicolumn{2}{|r|}{ D1 } & \multicolumn{2}{|r|}{$\mathrm{D} 2$} & \multicolumn{2}{|r|}{ D5 } & \multicolumn{3}{|c|}{ D10 } & \multicolumn{3}{|c|}{ D20 } \\
\hline & n. & s. & $\begin{array}{ll}\text { n. } & \text { s. }\end{array}$ & $\mathrm{P}$ & n. & s. & $\mathrm{n}$. & s. & $\mathrm{P}$ & $\mathrm{n}$. & s. & $\bar{P}$ \\
\hline Compras & 150 & 79 & $\begin{array}{|ll|}150 & 84\end{array}$ & & $150 \varepsilon$ & 85 & 150 & & & 150 & 92 & \\
\hline a favor & 81 & $29 \quad 1,09 \%$ & 6518 & $25,52 \%$ & 58 & $1811,44 \%$ & 53 & 17 & $9,16 \%$ & 40 & 5 & $95,67 \%$ \\
\hline contra & 69 & $5064,34 \%$ & 8566 & $24,91 \%$ & 92 & $6764,74 \%$ & 97 & 75 & $26,34 \%$ & 110 & 87 & $13,44 \%$ \\
\hline Vendas & 41 & 18 & 4121 & & 412 & 25 & 41 & 27 & & 41 & 30 & \\
\hline a favor & & $458,52 \%$ & 236 & $34,63 \%$ & 17 & $364,70 \%$ & 13 & 3 & $41,57 \%$ & 8 & 1 & $63,29 \%$ \\
\hline contra & 21 & $1474,36 \%$ & $18 \quad 15$ & $13,53 \%$ & 242 & $22 \quad 0,90 \%$ & 28 & 24 & $5,51 \%$ & 33 & 29 & $2,05 \%$ \\
\hline Int. a favor & 101 & $33 \quad 3,18 \%$ & $88 \quad 24$ & $26,50 \%$ & 752 & $2122,86 \%$ & 66 & 20 & $12,89 \%$ & 48 & 6 & $97,28 \%$ \\
\hline Int. $\mathrm{c}$ & 90 & $64 \quad 77,02 \%$ & 10381 & $16,70 \%$ & 1168 & $8930,05 \%$ & 125 & 99 & $11,58 \%$ & 143 & 116 & $3,38 \%$ \\
\hline \multicolumn{13}{|c|}{ Período Inteiro - 05/01/1999 - 31/12/2008 - Apenas as Intervenções Contínuas } \\
\hline & n. & s. & n. $\mathrm{s}$. & $\mathrm{P}$ & n. & s. & n. & s. & $\mathrm{P}$ & n. & s. & $\mathrm{P}$ \\
\hline Compras & 54 & 29 & 5430 & & 54 & 31 & 54 & 35 & & 54 & 39 & \\
\hline a favor & & $11 \quad 1,55 \%$ & 256 & $43,89 \%$ & & $8 \quad 14,94 \%$ & 21 & 7 & $12,99 \%$ & 10 & 1 & $75,60 \%$ \\
\hline contra & 28 & $18 \quad 86,15 \%$ & $29 \quad 24$ & $11,53 \%$ & 29 & $23 \quad 23,17 \%$ & 33 & 28 & $5,86 \%$ & 44 & 38 & $2,15 \%$ \\
\hline Vendas & 13 & 4 & $\begin{array}{ll}13 & 6\end{array}$ & & & 8 & 13 & 10 & & 13 & 10 & \\
\hline a favor & & $239,93 \%$ & 1 & $63,29 \%$ & 6 & $146,61 \%$ & 4 & 1 & $26,17 \%$ & 3 & 0 & $57,81 \%$ \\
\hline contra & 4 & $273,83 \%$ & 5 & $0,00 \% * * *$ & 7 & $7 \quad 0,00 \%$ & 9 & 9 & $0,00 \%$ & 10 & 10 & $0,00 \%$ \\
\hline Int. a favor & & $13 \quad 3,63 \%$ & $\begin{array}{ll}33 & 7\end{array}$ & $60,62 \%$ & 31 & $9 \quad 22,90 \%$ & 25 & 8 & $14,94 \%$ & 13 & 1 & $87,33 \%$ \\
\hline Int. c & 32 & $2091,96 \%$ & $34 \quad 29$ & $4,91 \% * *$ & 36 & $30 \quad 8,35 \%$ & 42 & 37 & $1,08 \%$ & 54 & 48 & $0,32 \%$ \\
\hline \multicolumn{13}{|c|}{ Subperíodo 3 - 12/08/2003 - 08/09/2008 - Todas as Intervenções } \\
\hline & n. & s. & n. $\mathrm{s}$. & $\mathrm{P}$ & n. & s. & $\mathrm{n}$. & s. & P & n. & s. & $\bar{P}$ \\
\hline Compras & 136 & 72 & 13675 & 136 & 76 & 136 & 84 & & 136 & 83 & & \\
\hline & 74 & $270,99 \%$ & 6218 & $18,79 \%$ & 56 & $18 \quad 8,54 \%$ & 49 & 16 & $8,36 \%$ & 35 & 4 & $95,90 \%$ \\
\hline contra & 62 & $45 \quad 62,38 \%$ & $74 \quad 57$ & $30,14 \%$ & 80 & $58 \quad 65,74 \%$ & 87 & 68 & $21,27 \%$ & 101 & 79 & $19,58 \%$ \\
\hline Int. a favor & 74 & $27 \quad 0,99 \%$ & $\begin{array}{ll}62 \quad 18 \\
\end{array}$ & $18,79 \%$ & 56 & $18 \quad 8,54 \%$ & 49 & 16 & $8,36 \%$ & 35 & 4 & $95,90 \%$ \\
\hline Int. contra & 62 & $45 \quad 62,38 \%$ & $74 \quad 57$ & $30,14 \%$ & 805 & $58 \quad 65,74 \%$ & 87 & 68 & $21,27 \%$ & 101 & 79 & $19,58 \%$ \\
\hline
\end{tabular}

respectivamente. 